\title{
Development of a Market Optimized Condensing Gas Water Heater
}

\author{
Final Technical Progress Report to: Department of Energy
}

Reporting Period - 10-1-99 - 06-30-05

Peter Pescatore

January 11, 2006

Contract Number DE-FC26-99FT40650

TIAX LLC

Acorn Park

Cambridge, MA

\begin{abstract}
Notices:
This report was prepared as an account of work sponsored by an agency of the United States Government. Neither the United States Government nor any agency thereof, nor any of their employees, makes any warranty, express or implied, or assumes any legal liability or responsibility for the accuracy, completeness, or usefulness of any information, apparatus, product, or process disclosed, or represents that its use would not infringe privately owned rights. Reference herein to any specific commercial product, process, or service by trade name, trademark, manufacturer, or otherwise does not necessarily constitute or imply its endorsement, recommendation, or favoring by the United States Government or any agency thereof. The views and opinions of authors expressed herein do not necessarily state or reflect those of the United States Government or any agency thereof.
\end{abstract}

Copyright (C) 2006 TIAX LLC. This paper was written with support of the U.S. Department of Energy under Contract No. DE-FC26-99FT40650. The Government reserves for itself and others acting on its behalf a royalty-free, nonexclusive, irrevocable, worldwide license for Governmental purposes to publish, distribute, translate, duplicate, exhibit and perform this copyrighted paper. 


\begin{abstract}
This program covered the development of a market optimized condensing gas water heater for residential applications. The intent of the program was to develop a condensing design that minimized the large initial cost premium associated with traditional condensing water heater designs. Equally important was that the considered approach utilizes design and construction methods that deliver the desired efficiency without compromising product reliability. Standard condensing water heater approaches in the marketplace utilize high cost materials such as stainless steel tanks and heat exchangers as well as expensive burner systems to achieve the higher efficiencies. The key in this program was to develop a water heater design that uses low-cost, available components and technologies to achieve higher efficiency at a modest cost premium. By doing this, the design can reduce the payback to a more reasonable length, increasing the appeal of the product to the marketplace.

Condensing water heaters have been in existence for years, but have not been able to significantly penetrate the market. The issue has typically been cost. The high purchase price associated with existing condensing water heaters, sometimes as much as $\$ 2000$, has been a very difficult hurdle to overcome in the marketplace. The design developed under this program has the potential to reduce the purchase price of this condensing design by as much as $\$ 1000$ as compared to traditional condensing units.
\end{abstract}

The condensing water heater design developed over the course of this program led to an approach that delivered the following performance attributes:

- $90 \%+$ thermal efficiency;

- 76,000 Btu/hr input rate in a 50 gallon tank;

- First hour rating greater than 180 gph;

- Rapid recovery time; and

- Overall operating condition well matched to combination heat and hot water applications

Over the final three years of the program, TIAX worked very closely with A.O. Smith Water Products Company as our commercial partner to optimize the design for manufacturing. This work included the initiation of a large field testing program (over 125 units) and an in-depth reliability program intended to minimize the risks associated with a new product introduction. At the time of this report, A.O. Smith plans to introduce this product to the marketplace in the early 2006 time period. 


\section{Table of Contents}

TABLE OF CONTENTS.......................................................................................................................II

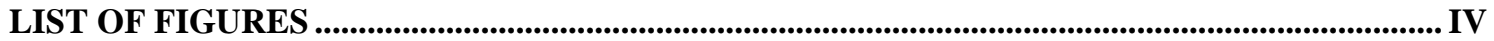

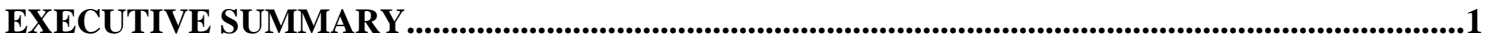

1.0 INTRODUCTION - PRELIMINARY IDENTIFICATION OF MARKET NEEDS ......... 1-1

1.1 IDENTIFYING THE PREFERRED HEAT EXCHANGER APPROACH AND DEVELOPING THE INITIAL

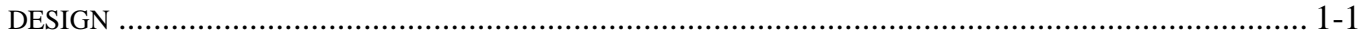

1.2 FABRICATION AND TESTING OF REFINED PROTOTYPES...................................................... 1-2

1.3 FURTHER REFINEMENT OF TARgET MARKETS AND CONSUMER NEEDS …….............................. 1-4

1.4 Developing And Testing of a Refined Design to MeEt Revised Market NeEdS .............. 1-5

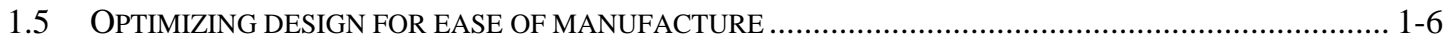

1.6 DEVELOPMENT AND EXECUTION OF A DETAILED RELIABILITY PROGRAM ……........................... 1-7

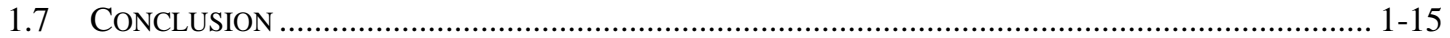




\section{List of Figures}

Figure 1: Early Design o Market Optimized Condensing Water Heater ...................... 1-2

Figure 2: Refined Hat Exchanger Design. ......................................................... 1-3

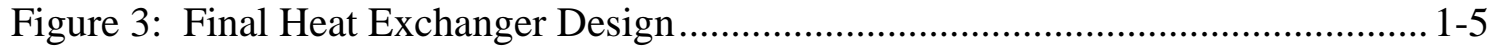

Figure 4: Transition Region of Concern .............................................................. 1-8

Figure 5: Effect of Average Tank Water Temperature on Exhaust Temperature....... 1-11

\section{List of Tables}

Table 1: Performance Summary of the High Efficiency Water Heater ....................... 1-3

Table 2: Snapshot of Combination Heat and Hot Water Markets. .............................. 1-4

Table 3: Performance Results for Refined Prototype ............................................ 1-6 
Re: D0012

Powered by

Innovation since 1886

\section{Executive Summary}

Water heating accounts for $11 \%$ of the total energy consumed in buildings. Many factors, especially flue standby losses, limit the efficiency of currently available mass marketed water heaters. Some products do exist on the marketplace that exhibit higher efficiencies, but these products tend to be much more expensive than the traditional storage water heaters. One manufacturer offers a condensing residential water heater with an energy factor of .86 on the market for $\$ 2000$. The designers and manufacturers of these higher efficiency water heaters have used a high cost materials approach, utilizing stainless steel tanks and heat exchangers as well as expensive burner systems to achieve the higher efficiencies. In addition to the cost impact, these stainless steel tanks bring with them a host of difficulties in the manufacturing process with regard to tank welding and overall product reliability. The increased costs and suspect reliability associated with the high efficiency water heaters currently on the market make them less than desirable for many consumers.

As currently available high efficiency units bring with them increased cost and in many cases decreased reliability, there is a tremendous opportunity for a cost optimized high efficiency water heater. Such a water heater has to utilize design and construction approaches that deliver the desired efficiency at a reasonable cost and without compromising product reliability. The key is to develop a water heater design that uses low-cost, available technologies to achieve higher efficiency with a modest cost premium. Such a design will reduce the payback time from energy savings to a more reasonable length and make the product more appealing to the marketplace.

The focus of the work on this program was to develop a design that utilized as many standard water heater components as possible. This included utilizing standard tank materials and sizes, insulation, jackets, burner and ignition systems and gas valving. The program's initial task focused on developing a heat exchanger approach that could meet the competing goals of high efficiency and low cost. As the design was refined, numerous market studies and marketing input from our commercial partner led to increased burner input rates to meet the needs of a wider market. Key to the overall development of the final design was the use of a glass-lined heat exchanger that could be made from inexpensive low carbon steel. The cost savings realized from such an approach, as compared to stainless steel heat exchangers, is significant.

For the condensing water heater, the product development effort was spread across eight key tasks:

- Preliminary identification of market needs;

- Identifying the preferred heat exchanger approach and developing the initial design;

- Fabrication and testing of initial and refined prototypes;

- Further refinement of target markets and consumer needs;

- Development and testing of a refined design to meet the revised market needs:

- Optimizing design for ease of manufacture; 
- Development and execution of a detailed reliability program;

- Field testing and product introduction

A.O. Smith identified three key markets for the design that was being developed:

- Large, high end residential homes;

- Combination heat and hot water residential applications, including in-floor radiant heating systems;

- Light commercial applications, such as fast food restaurants.

The end result was a condensing water heater that had the following attributes:

- $90 \%+$ thermal efficiency;

- $76,000 \mathrm{Btu} / \mathrm{hr}$ input rate in a 50 gallon tank;

- Significant recovery capability to meet the needs of the target market;

- First hour rating greater than 180 gph.

The design has progressed through A.O. Smith's product development process and is scheduled to be introduced to the marketplace in early 2006. 


\subsection{Introduction - Preliminary Identification of Market Needs}

The efficiencies of mass marketed water heaters are quite low and currently available high efficiency units bring with them increased cost and in many cases decreased reliability. Therefore, there is a tremendous opportunity for a cost optimized high efficiency water heater. Such a water heater has to utilize design and construction approaches that deliver the desired efficiency without compromising product reliability. The key is to develop a water heater design that uses low-cost, available technologies to achieve higher efficiency with a modest cost premium. Such a design will reduce the payback time from energy savings to a more reasonable length and make the product more appealing to the marketplace.

At the start of this program, extensive market information gathered by the Gas Technology Institute (formerly the Gas Research Institute) and Enbridge Consumers Gas in Ontario was utilized to guide the initial development. This data showed a large market need for a high efficiency water heater capable of being applied in combination heat and hot water applications in the Southern US and in high efficiency new construction in Canada. This market information led to an initial target input rate of $50,000 \mathrm{Btu} / \mathrm{hr}$.

\subsection{Identifying the Preferred Heat Exchanger Approach and developing the initial design}

There were three classes of design of a convective heat exchanger for a water heater that were considered in this investigation. These were:

A) Flue tube inside the water tank;

B) Combination of flue tube inside the tank transitioning to a flue outside of the tank;

C) Side arm heat exchanger with water circulation to the tank.

In the original proposal, five approaches were identified that fit within these three classifications of heat exchanger approaches.

The methodology used for developing and analyzing each design approach was to first perform a theoretical evaluation to determine key parameters in the system such as heat exchanger area needed. A theoretical heat exchanger model was used to predict the system characteristics. Experiments were then conducted with the prototypes to verify the models. Since the main objective of the program was to develop a water heater design that delivers higher efficiency with a reasonable payback period, a costing analysis was performed for each of the design concepts and included as part of the design evaluation.

Since each design approach has its own set of benefits and drawbacks, cost considerations alone were not sufficient enough to select a preferred approach. A decision matrix containing the most important design criteria was created so that these characteristics could be measured and compared. Criteria considered included 
manufacturability, reliability, installation considerations, cost and performance. Working with our commercial partner, we ranked each approach against each criterion and identified a preferred heat exchanger approach. An early embodiment of this approach is shown in Figure 1.

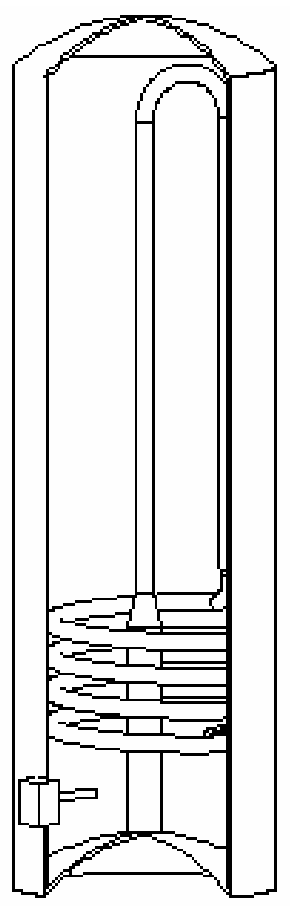

Figure 1: Early Design o Market Optimized Condensing Water Heater

\subsection{Fabrication and testing of refined prototypes}

As testing progressed with the prototype in Figure 1, some design shortcomings were identified. Key amongst these shortcomings was a problem with stacking of water temperatures in the tank after successive draws. When tested to the appropriate ANSI test conditions, the design failed the stacking test. Modeling with a computer software program called Fluent helped to identify means to reduce this stacking. This modeling showed that the heat exchanger needed to be redesigned to remove the length of the large U-tube that goes to the top of the tank and replace it with extra length within the helix coil. Figure 2 shows what this new design configuration looked like in both CAD drawings and in a photograph of the prototype heat exchanger. 

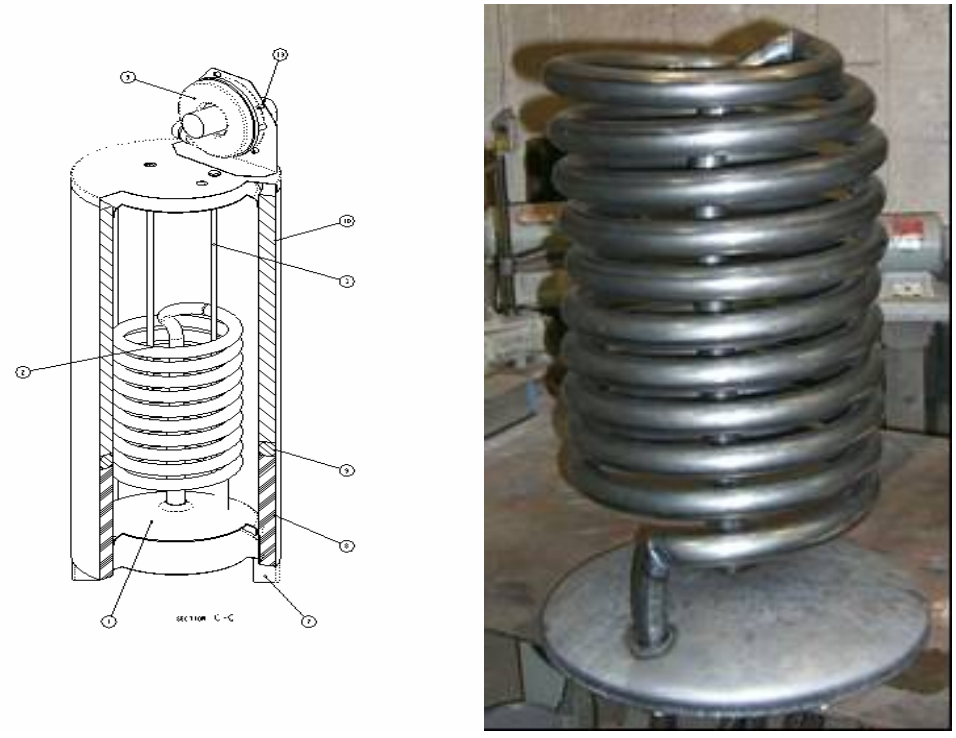

Figure 2: Refined Heat Exchanger Design.

Several tests were performed on the refined prototype including the 24-hr simulated use test, the first hour rating test, and an ANSI stacking test. The results of these tests are compared to a typical 50-gallon power vented water heater in Table 1.

Table 1: Performance Summary of the High Efficiency Water Heater

\begin{tabular}{|l|c|c|}
\hline \multicolumn{1}{|c|}{$\begin{array}{c}\text { Performance } \\
\text { Characteristic }\end{array}$} & $\begin{array}{c}\text { High Efficiency } \\
\text { Design }\end{array}$ & $\begin{array}{c}\text { Typical Power Vent } \\
\text { Design }\end{array}$ \\
\hline Tank Size & $50 \mathrm{gal}$ & $50 \mathrm{gal}$ \\
\hline Firing Rate & $58,500 \mathrm{Btu} / \mathrm{hr}$ & $65,000 \mathrm{Btu} / \mathrm{hr}$ \\
\hline Energy Factor & 0.78 & 0.55 \\
\hline First Hour Rating & $110 \mathrm{gal}$ & $93 \mathrm{gal}$ \\
\hline Stacking & $10^{\circ} \mathrm{F}$ & $\leq 30^{\circ} \mathrm{F}$ \\
\hline Heat Exchanger Efficiency & $92 \%$ & - \\
\hline Recovery Efficiency & $86 \%$ & $75 \%$ \\
\hline
\end{tabular}

A 24-Hour Simulated Use Test (energy factor test) was performed according to Code of Federal Regulations(CFR) Pt. 430, Subpt. B, App. E. The 24 hour simulated use test consists of six water draws of 10.7 gallons made during the first six hours of the test. Following the water draws, the water heater sits in the standby mode until the end of the 24-hour period. Various data is collected including average tank water temperature, delivery temperature, inlet temperature, and gas consumed. This data provides sufficient information to calculate the energy factor, shown in Table 1, which is an indication of how efficiently the prototype will operate under typical residential conditions. 


\subsection{Further Refinement of Target Markets and Consumer Needs}

With a preferred approach in place and a significant amount of testing and experience gained from the refined prototype, a more in-depth market analysis was done to identify where the best market potential exists for this design. TIAX and A.O. Smith Marketing identified the need to further investigate potential high efficiency water heater markets before the product specifications could be fully developed. The radiant floor heating market was identified as one potential area that needed further investigation.

Information on radiant in-floor heating systems was compiled from a variety of sources:

- Discussions with Radiant Panel Association (RPA);

- Interviews with installers of radiant panel heating systems;

- $\quad$ A.O. Smith marketing experience in radiant systems.

What was found from these various sources was that the radiant floor market could be described as follows:

- $\quad$ Typical new installation is in a $3000 \mathrm{ft}^{2}$ home;

- $\quad$ Average heat rate for new home installation is about $20 \mathrm{Btu} / \mathrm{ft}^{2}(60 \mathrm{kBtuH})$;

- There is limited furnace and boiler availability at this capacity;

- $\quad$ The higher costs of boiler systems make a water heater option attractive;

- Many systems exist where the water heater is used for both domestic hot water and smaller radiant systems such as kitchen and bath only applications;

- A significant market potential exists for an affordable, high efficiency water heater that can meet the needs of the radiant in-floor market.

Based on this information, A.O. Smith Marketing projects significant growth in the residential in-floor heating market and hopes to capture a significant share of this growth. Table 2 presents a snapshot of the hydronic market and its growth potential.

Table 2: Snapshot of Combination Heat and Hot Water Markets.

\begin{tabular}{|r|c|c|c|c|c|}
\cline { 2 - 6 } \multicolumn{1}{c|}{} & 1991 & \multicolumn{2}{c|}{2002} & \multicolumn{2}{c|}{$\begin{array}{c}2005 \\
\text { Projected }\end{array}$} \\
\hline $\begin{array}{c}\text { Installation } \\
\text { Type }\end{array}$ & $\begin{array}{c}\text { Market } \\
\text { Volume }\end{array}$ & $\begin{array}{c}\text { Market } \\
\text { Volume }\end{array}$ & $\begin{array}{c}\text { Water Heater } \\
\text { Market Share }\end{array}$ & $\begin{array}{c}\text { Market } \\
\text { Volume }\end{array}$ & $\begin{array}{c}\text { Water Heater } \\
\text { Market Share }\end{array}$ \\
\hline Forced Air & 60,000 & 120,000 & 118,000 & 140,000 & 138,000 \\
\hline In-floor radiant & 9,000 & 80,000 & 6400 & 130,000 & 47,000 \\
\hline Total & $\mathbf{9 6 , 0 0 0}$ & $\mathbf{2 0 0 , 0 0 0}$ & $\mathbf{1 2 4 , 4 0 0}$ & $\mathbf{2 7 0 , 0 0 0}$ & $\mathbf{1 8 5 , 0 0 0}$ \\
\hline
\end{tabular}


Based on this market analysis on the radiant panel market and significant experience in the water heating industry, A.O. Smith Marketing identified potential in three key markets for this new condensing water heater design:

- Combined water heating and space conditioning including in-floor radiant systems;

- $\quad$ High end residential water heating only;

- Light commercial applications.

To meet the needs of these markets, the condensing unit's input rate needed to be much higher than the 58,500 Btu/hr rate at which it was currently operating. Further analysis of these markets showed an input rate around 75,000 Btu/hr to be ideal to meet these needs.

\subsection{Developing and Testing of a Refined Design to Meet Revised Market Needs}

With the need identified for a higher input rate, work began on refining the design. Key concerns for operating at this higher input included whether there was sufficient combustion chamber volume for clean combustion and maintaining the $90 \%$ plus efficiency necessary to satisfy market needs. The heat exchanger was redesigned in order to deliver the necessary area to transfer the additional heat generated by the higher input rate. A.O. Smith invested significant capital into obtaining the necessary tooling to build heat exchangers to this new design. As part of this process, numerous heat exchangers were constructed and evaluated for porcelain coating and projected performance capabilities. The final version of the heat exchanger is shown in Figure 3.
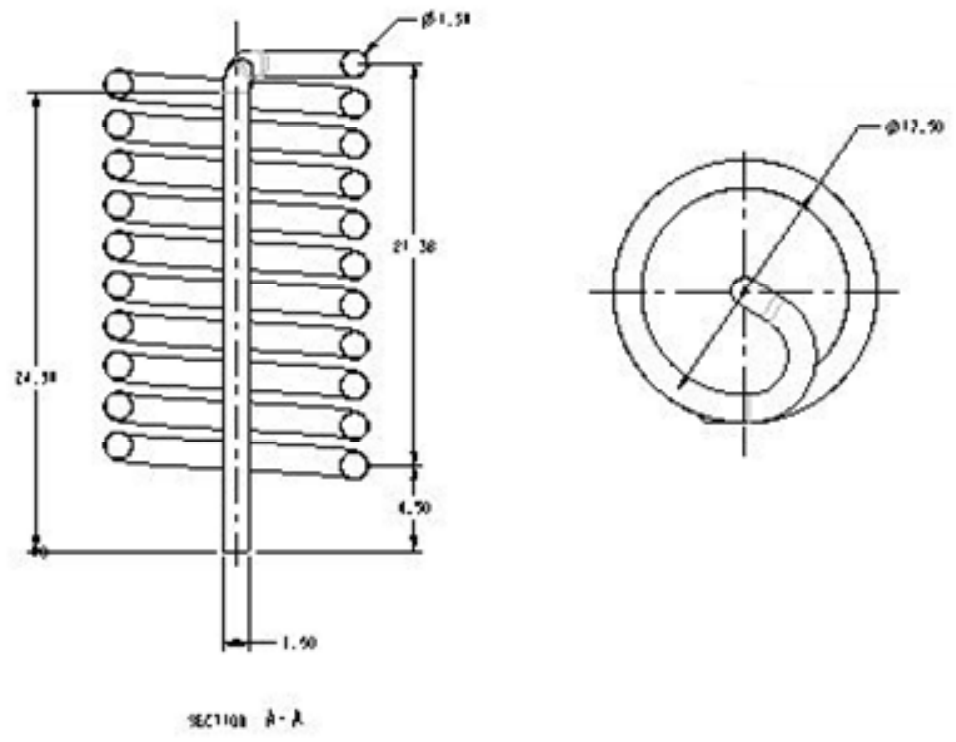

\section{Figure 3: Final Heat Exchanger Design}

This refined heat exchanger was then installed into a State Industries (owned by A.O. Smith) 50 gallon high dome power vent unit and adjusted to an input rate of 76,000 
Btu/hr. Various performance tests were conducted on this unit including the DOE First Hour Rating, DOE 24-hr Simulated Use Test and ANSI stacking testing. The results are summarized in Table 3.

Table 3: Performance Results for Refined Prototype

\begin{tabular}{|l|c|c|}
\hline \multicolumn{1}{|c|}{ Performance Characteristic } & Performance Target & Testing Results \\
\hline Tank Size / Type & $50 \mathrm{gal} / \mathrm{High}$ Dome & $50 \mathrm{gal} / \mathrm{High}$ Dome \\
\hline Firing Rate & $\sim 75,000 \mathrm{Btu} / \mathrm{hr}$ & $77,000 \mathrm{Btu} / \mathrm{hr}$ \\
\hline Energy Factor & 0.78 & 0.78 \\
\hline First Hour Rating & $180 \mathrm{gal}$ & $180 \mathrm{gal}$ \\
\hline Stacking & $<30^{\circ} \mathrm{F}$ & $26^{\circ} \mathrm{F}$ \\
\hline Recovery Efficiency & $90 \%$ & $90.4 \%$ \\
\hline
\end{tabular}

Note that test standards for energy factor and first hour rating do not apply to units operating over $75,000 \mathrm{Btu} / \mathrm{hr}$. The data is presented here for comparison purposes only.

\subsection{Optimizing Design for Ease of Manufacture}

At this point in the program, A.O. Smith was well committed toward commercializing the design. A large potential market had been identified, performance targets had been met and the necessary tooling was in place to make the heat exchanger at A.O. Smith's McBee, South Carolina facility. The focus now shifted toward the overall design and making the new product as easy to manufacture as possible.

This multi-month effort led to the identification of numerous modifications to optimize the design and approach for manufacturing. These design improvements included:

- Modifications to tank assembly for better fit with existing product lines;

- Redesign and orientation of anode rod for improved performance;

- Modification to top cover tooling to match existing parts;

- Addition of bead and crimp to jacket to help locate top cover;

- Modification of inner door grommet hole to accept new igniter;

- Development of new igniter assembly design;

- Increased overall tank height of 1" to meet tank capacity goal;

- Development of condensate trap design;

- Modifying radiation shield to improve combustion performance; 
To verify these design and manufacturing improvements, a new unit was built in December, 2004 and tested for efficiency, combustion and a select set of ANSI certification tests. The performance results were consistent with those reported in Table 3. At this point, the design was approved by A.O. Smith and work began on building multiple units for reliability and field testing.

\subsection{Development and Execution of a Detailed Reliability Program}

\section{Preliminary Test Plan - Component Breakdown / Failure Analysis}

Water heaters are typically expected to operate reliably for approximately 5-10 years. Due to its cost premium, we would expect this design to be at the upper end of this range. It is neither practical nor reasonable to wait 10 years to determine the reliability of the design, so alternative methods are needed. Through the use of accelerated testing, the required testing time can be dramatically reduced. A first pass review of each component of this design was performed in order to determine possible failure modes. Representatives from A. O. Smith, TIAX and GTI took part in this review. Since the heart of the design approach from the beginning of the program was to utilize as many standard water heater components as possible, the focus of the review and the resultant reliability testing focused on the new components, namely the enameled helix heat exchanger and the induced draft blower.

In reviewing the design of the heat exchanger, two areas of concern were identified. The first is corrosion of the inside of the tube due to successive wet/dry cycles of the highly acidic condensate formed from the exhaust gas. The second area of concern is the possibility of excessive wear of the enamel on the outside of the tube due to thermal cycling. This cycling could lead to a weakening of the enamel bond, resulting in a greater risk of corrosion of the heat exchanger tube. The transition region where the vertical flue transitions to the helix coil (Figure 4) was identified as the area of greatest concern for the effects of thermal cycling. 


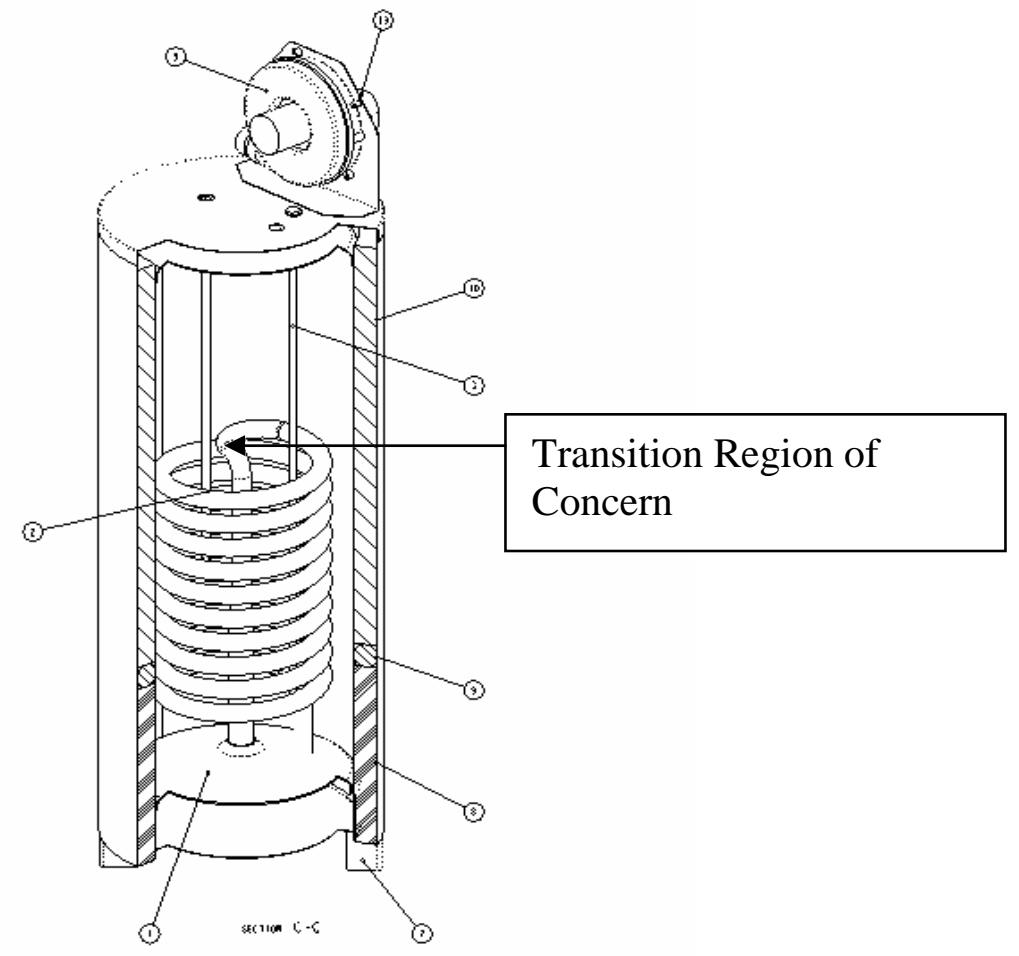

Figure 4: Transition Region of Concern

The other key new component of concern for this new water heater design is the blower motor. This motor is a new product for this application, but has been used reliably in other applications. During the course of the planned cycling tests, the blower motor would be subjected to a high number of on/off cycles, providing the necessary indication of reliability.

The goal of accelerated testing is to maximize the challenge on components without introducing new failure modes. In the case of this design, the focus of the testing is on the enamel coating on the inside and outside of the helix coil. In designing an accelerated test for the inside of the coil, the key parameters to consider is the generation of condensate which coats the walls of the tube and the eventual drying of the condensate after the water heater has recovered to its setpoint. This wet dry process is a key stress on the enamel and has the risk of eventual steel corrosion. Over the lifetime of the product, the inside of the coil will be exposed to condensate wet/dry cycles that will leave behind cumulative layers of acidic coatings that could lead to a degradation of the enamel coating, and, in turn, corrosion of the helix coil itself.

In going through the process of laying out and defining the appropriate tests to run, it is important to examine the likely market scenarios for this design. As detailed earlier, A.O. Smith marketing identified three key markets that they are targeting this design towards. These are: 
1) Combined water heating and space conditioning including in-floor radiant heating;

2) High end residential water heating only;

3) Light commercial (non-china restaurant) applications

In designing the tests to be run, it is important to consider the range of conditions that might be encountered in any of these applications.

\section{Key Variables}

An accelerated life test to rule out excessive heat exchanger corrosion was developed and consisted of repeated cycles of drawing water and allowing the system to recover to the set point. Many variables affect the design of these cycles. These variables include:

- Input rate;

- Inlet water temperature;

- Ambient air temperature;

- Thermostat setting;

- Draw off rate;

- Quantity of draw;

- Recovery time;

- Time between draws;

- Fuel used.

\section{Input rate}

Nominally, this design has an input rate of 76,000 Btu/hr. However, in actual field applications, the actual input rate will vary from this number. Variations in gas composition, gas line pressures and other external factors could affect the nominal rate by as much as $5-10 \%$. Since these variations can be hard to predict, high and low ranges rate were selected based upon ANSI test standard conditions of overfire and underfire. In these tests, the gas inlet pressure is adjusted up or down to account for possible infield variations.

\section{Inlet water}

Inlet water temperature can vary greatly from region to region and season to season. $40^{\circ} \mathrm{F}$ inlet water is quite standard during mid winter in colder climates. In a hydronic system, return water temperatures around $115^{\circ} \mathrm{F}$ are typical. In between, there is a wide range of possible conditions. While the extremes will have the largest impact on condensate formation and heat exchanger surface temperatures, inlet water temperatures in the nominal range of $70^{\circ} \mathrm{F}$ also need to be considered since the vast majority of units will operate close to this condition. 
Re: D0012

Powered by

Innovation since 1886

Ambient air temperature

While this design is intended for indoor applications, the ambient conditions around the water heater can vary greatly across installations. In general, though, the majority of installations will be in $75^{\circ} \mathrm{F}+/-10^{\circ} \mathrm{F}$ ambient conditions.

\section{Thermostat setting}

Since one of our key goals is to drive the wet/dry cycles in this process in order to stress the inside of the helix coil, tank setpoint is an important variable in the process.

Setpoints that are chosen need to be consistent with what is typical in the field. In a GRI Topical Report ${ }^{1}$ on residential hot water usage, a range of set points in the field was given as $115-145^{\circ} \mathrm{F}$. A cooler tank will create more condensate while a hotter tank will

speed the heat exchanger drying process. Too high of a setpoint will result in little or no condensate formation. Water vapor will condense when the combustion products are cooled to $132^{\circ} \mathrm{F}$ or lower. Tank setpoints need to be chosen such that sufficient condensate is formed without resulting in an excessive amount of time for the heat exchanger to dry out between draws. Based on this, a nominal setpoint of $135^{\circ} \mathrm{F}$ was selected. This temperature is within typical residential setting range in the field with the added benefit of speeding up the drying process. For those tests intended to simulate use with hydronic heating equipment, a tank setting of $140^{\circ} \mathrm{F}$ was chosen. For use in light commercial applications, a thermostat setting of $180^{\circ} \mathrm{F}$ was specifeid. This setting will result in the maximum external heat exchanger temperature and will serve to best stress the enamel with little or no condensate formation.

\section{Draw-off rate}

The draw off rate for the DOE's "24-hr Simulated Use” and "First Hour Recovery" tests is $3.0 \pm 0.25 \mathrm{gpm}$. A typical shower head requires about $1.3 \mathrm{gpm}$ of water from a water heater tank combined with about 1.3 gpm of unheated water. It is expected that the draw rate of most common hot water applications will fall in this range. During a draw, the cool water is introduced at the bottom of the tank through a dip tube. The key here is to expose the lower regions of the heat exchanger to as cold a water temperature as is reasonable. The effect of average tank water temperature on exhaust temperature is shown in Figure 5. Exhaust temperatures below $132^{\circ} \mathrm{F}$ are needed for condensate to form in the tube. To maximize the region of condensate production, an exhaust temperature below $132^{\circ} \mathrm{F}$ is necessary. To achieve this condition, a higher water flow rate of $2.5 \mathrm{gpm}$, representing two concurrent showers, was chosen.

In hydronic systems, the return flow rate is driven by the air handler system or circulator. Measurements from an ongoing field test program being conducted by GTI have shown this rate to be as high as 6 gpm. In commercial applications, the flow rate can be significantly higher. For instance, during a busy meal time in a fast food

\footnotetext{
${ }^{1}$ Residential Hot Water Usage: A Review of Published Metered Studies
} 
restaurant, a flow rate as high as $10 \mathrm{gpm}$ could be needed to fill multiple sinks for washing pots and pans.

\section{Quantity of each draw}

Using water usage data from several sources ${ }^{2}$ it was estimated that the average draw from a hot water tank in a standard residential application is about 13 gallons. It is our experience that a draw of as little as 4 gallons can cause the burner to fire, and would therefore result in condensate production. Drawing larger amounts of water would cause a larger portion of the heat exchanger to become moist and thus require more time for drying to complete. Drawing smaller amounts of water would speed up the required drying time but limit the area exposed to condensation and corrosion. Since we are striving for wet/dry cycles, it is only necessary to make sure the burner turns on long enough to create sufficient condensation over as much of the heat exchanger surface as is reasonable. A 25-gallon draw was found to be sufficient to represent nominal conditions. In other applications, especially light commercial applications, the water draw offs will be quite different. It is easy to imagine a scenario where the whole contents of the storage tank is drawn down during a busy time of the day. The quantities associated with this type of test are those sufficient to completely "turn over" the hot water in the tank. For these applications, 80 gallons of total flow was selected.

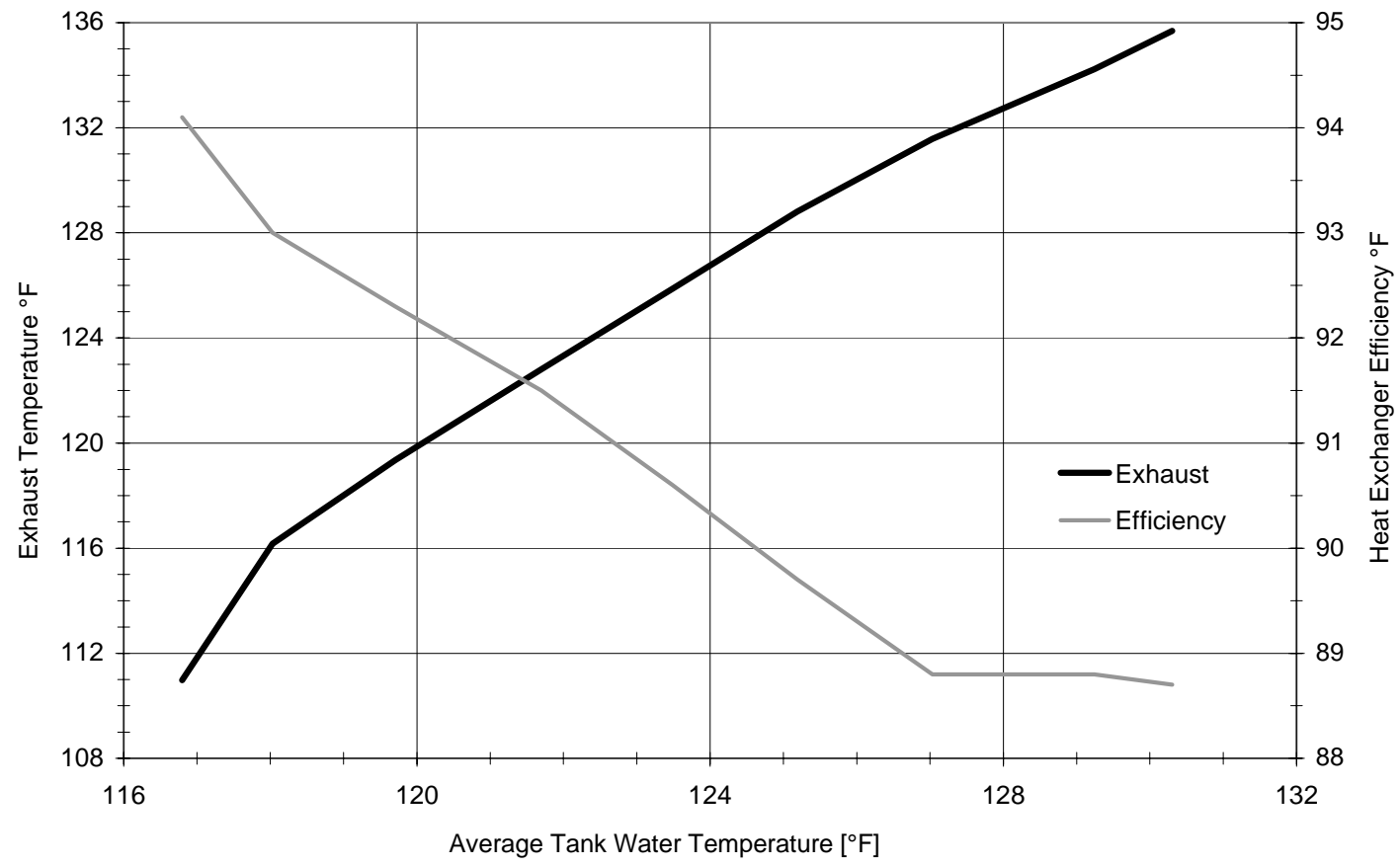

Figure 5: Effect of Average Tank Water Temperature on Exhaust Temperature

Recovery time and time between draws

\footnotetext{
${ }^{2}$ City of Albuquerque: Water Conservation Office; Rensselaer Polytechnic Institute: Water Conservation Web site
} 
The recovery time for each test condition will vary greatly, based upon the setpoint, inlet water temperature, and water flow rate. In most cases, time between draws will be driven by the amount of time needed to fully dry the heat exchanger after a draw. Significant testing was performed on the refined prototype to determine what the recovery times for different scenarios needed to be.

\section{Fuel}

This design is intended to be made available in both natural gas and propane configurations. Within each fuel type, there could also be wide variations, but this is outside the scope of this work.

\section{Test Conditions}

If every combination from Table 4 were to be considered, 1944 tests would need to be run. In narrowing down the variables, fuel was restricted to natural gas only since propane units will not be part of the initial build. Ambient air temperature was identified as having little or no effect on the key parameters to be tested (condensate generation inside the helix coil and thermal cycling on the outside).

\section{Table 4 Summary of Variable Range of Conditions}

\begin{tabular}{|l|l|}
\hline Variables & Settings \\
\hline Input rate & High, Nominal, Low \\
\hline Inlet Water Temp & High (115), Medium (70), Low (40) \\
\hline Ambient Air Temp & High (85), Medium (75), Low (65) \\
\hline Thermostat Setting & $180,140,120$ \\
\hline Draw flow rate & $3 \mathrm{gpm}, 6 \mathrm{gpm}, 10 \mathrm{gpm}$ \\
\hline Draw duration & 5 minutes, 10 minutes \\
\hline Time between draws & 5 minutes, 60 minutes, 720 minutes \\
\hline Fuel & Natural gas, propane \\
\hline
\end{tabular}

Even with these reductions in variables and settings/levels, there are still over 300 combinations that could be considered. A.O. Smith, GTI and TIAX staff met in July, 2004 to collectively select a reduced set of tests that would capture the true spirit of the accelerated testing, namely the corrosion issues identified earlier. This led to the identification of the following five tests conditions as shown in Table 5. 
Re: D0012

Powered by

Innovation since 1886

Table 5 Accelerated Testing Conditions

\begin{tabular}{|l|c|c|c|c|l|}
\hline & Condition \#1 & Condition \#2 & Condition \#3 & Condition \#4 & Condition \#5 \\
\hline Firing Rate & Nominal & High & Low & Medium & Medium \\
\hline Inlet Water & 58 & 115 & 40 & 40 & $\begin{array}{l}40 \text { tap, } \\
115 \text { hydronic }\end{array}$ \\
\hline Setpoint & 135 & 140 & 120 & 180 & 140 \\
\hline $\begin{array}{l}\text { Draw flow, } \\
\text { gpm }\end{array}$ & 2.5 & 6 & 8 & 5 & $\begin{array}{l}5 \text { tap, } \\
6 \text { hydronic }\end{array}$ \\
\hline $\begin{array}{l}\text { Draw } \\
\text { duration }\end{array}$ & 10 & 20 & 10 & 10 & $\begin{array}{l}10 \text { tap, } \\
20 \text { hydronic }\end{array}$ \\
\hline $\begin{array}{l}\text { Standby } \\
\text { between } \\
\text { tests }\end{array}$ & 40 & 15 & 30 & 40 & $\begin{array}{l}40 \text { tap, } \\
40 \text { hydronic }\end{array}$ \\
\hline
\end{tabular}

These tests can be further summarized as follows:

Test Condition \#1 represents more standard conditions for inlet water temperature, water heater setpoint, draw flow rate and draw duration. In a typical household, hot water is used for showers, dishwashers, laundry, and faucets. In order to develop a representative repeating cycle, certain estimates and assumptions were made regarding a typical daily cycle. According to the Commercial Water Heating Applications Handbook $^{2}$, it is estimated a typical family uses 63 gallons of hot water per day. We assumed the bulk of this usage is for showers and a typical household takes three showers per day. We concluded the test cycle and acceleration factor would be based on three ten-minute cycles of 25-gallon draw-off each per day. This type of cycling would put the test conditions on the high end of daily household hot water usage.

Test Condition \#2 is representative of a hydronic only application. The flow rates and durations would be toward the upper end of those measured by GTI in field hydronic systems. The setpoint and inlet water temperature are consistent with those experienced in hydronic applications.

Test Condition \#3 is representative of a high end residential system in winter conditions. The inlet water temperature of $40^{\circ} \mathrm{F}$ is typical of northern climates. The flow rate and draw duration is consistent with filling a hot tub or whirlpool bath.

Test Condition \#4 is representative of a light commercial scenario. Setpoint temperature is significantly higher $\left(180^{\circ} \mathrm{F}\right)$ and the flow rates and durations are such that they empty the tank of all its hot water. This test condition is expected to be the most stressful one for the failure mode of thermal cycling on the external enamel.

Test Condition \#5 is representative of a mixed hydronic and potable water system. Setpoint and inlet water conditions are consistent with hydronic operations in colder climates. Flow rates for both the hydronic and tap water systems are at the high end of the typical range. 
Ten units (8 condensing and 2 standard) were divided up amongst the testing labs at TIAX, GTI and A.O. Smith as follows:

\begin{tabular}{|c|c|c|c|}
\hline Unit & Type & Test Location & Test Condition \\
\hline 1 & Condensing & GTI & 1 \\
\hline 2 & Condensing & GTI & 3 \\
\hline 3 & Condensing & GTI & 4 \\
\hline 4 & Condensing & TIAX & 1 \\
\hline 5 & Condensing & TIAX & 2 \\
\hline 6 & Condensing & TIAX & 5 \\
\hline 7 & Standard Power Vent & GTI & 1 \\
\hline 8 & Standard Power Vent & TIAX & 1 \\
\hline 9 & Condensing & A.O. Smith & 2 \\
\hline 10 & Condensing & A.O. Smith & 3 \\
\hline
\end{tabular}

Based on the GRI report mentioned earlier, a typical usage of 63 gallons per day can be expected in most households. Using an average household draw of 13 gallons and a total usage of 63 gallons per day, 5 wet/dry cycles approximates one day of use. Each day of the accelerated test the water heater will cycle 48 for an acceleration factor of almost 10 . Ten years of actual operation is equivalent to 18,250 cycles or 380 days of accelerated testing. This time frame is beyond the scope of this program and is unreasonable for the industry in general. Based on previous TIAX and A.O. Smith experience with accelerated testing of new water heater designs, a more reasonable length of time for testing is 3-4 months of cycling. Experience has shown that this length of time is sufficient to gain an indication if new components, especially the heat exchanger and associated welds, are more likely to fail than current standard components. By periodic inspection of the areas of concern, we will have an indication of rate of degradation and can use this to predict the overall product life.

In order to confirm that the test is operating as designed, several variables were measured. The inlet water temperature is important because it will affect the amount of condensation that will form in the heat exchanger. Other measurements included:

- $\quad$ condensate production, which will affect the wetness of the heat exchanger wall;

- $\quad$ ambient temperature and humidity, which may indicate the drying of condensation between cycles;

- water flow rate during the draw, which will affect the amount of cold water introduced at each draw;

- $\quad$ exhaust temperature, which will provide an indication for variation in unit efficiency over the course of tests; and

- the tank water temperature, which will confirm the consistent operation of the thermostat. 


\section{Current Status - Reliability and Field testing and the Future for the design}

At the time of this report, cycle testing has taken place at A.O. Smith, GTI and TIAX. This testing was completed in the early fall of 2005 outside the budget of the DOE program. A 120 unit field test has also been undertaken by A.O. Smith with assistance from GTI through their member utilities. In many cases, the units were installed into homes that utilize the extra capacity for combination heat and hot water systems. A.O. Smith continues to invest significant capital and manpower toward developing the necessary capabilities to produce the design in mass quantities. At this time, an early 2006 product launch is anticipated.

\subsection{Conclusion}

A market optimized, condensing gas water heater design has been developed by TIAX and its commercial partner, A.O. Smith with assistance from GTI. Through implementation of an approach that sought to utilize as many standard water heater components as possible, significant cost savings have been realized with this design as compared to existing condensing water heaters on the marketplace. Significant market and consumer studies have identified combination heat and hot water applications as an ideal market to target for introduction of this design. This includes the rapidly growing radiant in-floor heating market. Other target markets include high-end residential hot water systems and light commercial markets.

As the commercial partner, A.O. Smith has invested significant capital and manpower into refining the design for manufacturing and increasing the capability of their production plant in McBee, South Carolina to be in a position to manufacture this design in quantity. A detailed and extensive product reliability testing program, augmented by an extensive field test program, intended to identify potential weak points in the design has been performed.

The end result of this research effort will allow consumers the opportunity to purchase a reasonably priced, high efficiency water heater. An early 2006 product launch by A.O. Smith is planned. 